\title{
Pressure Ulcers in Pediatric Patients: Risk Factors and its Prevention
}

\author{
Sanju Pukhraj Khawa \\ Nursing Officer, \\ Department of Nursing, All India Institute of Medical Sciences, Jodhpur, Rajasthan, India
}

DOI: 10.29322/IJSRP.11.08.2021.p11673

http://dx.doi.org/10.29322/IJSRP.11.08.2021.p11673

\begin{abstract}
Pressure ulcers are one of the most common issues among children admitted in intensive care units or those who are critically ill. There is abundant data regarding incidence and risk factors of pressure ulcers among hospitalized adults but when children literature is considered, the data is limited. There are limited evidences that support incidence and prevalence of pressure ulcers in children because their anatomy and physiology is completely different from adults. Also, various guidelines and treatments taken from adult care in order to prevent risk of pressure ulcers among children does not evidence based data.
\end{abstract}

Index Terms- pressure ulcers; pediatric patients; prevention of pressure ulcers; risk factors.

\section{INTRODUCTION}

The Pediatric Intensive Care Unit (PICU) is a unit that focuses on care and treatment for critically ill pediatric patients. Critically ill patients require intensive care under which the patient is closely and continuously monitored because they are hemodynamically altered. [1] These children are either partially or completed dependent on health care providers. Therefore they are more prone for development of pressure ulcers. The prevalence of pressure injuries among hospitals is varied. It ranges from 3 to $10 \%$ among total pediatric populations admitted in health care setting. [2]

A pressure injury or ulcer is defined by the National Pressure Ulcer Advisory Panel (NPUAP) as localized damage to the skin and underlying soft tissue usually over a bony prominence or injury related to medical or other devices. The injury occurs as a result of intense and/or prolonged pressure or pressure in combination with shear stress. The NPUAP has defined pressure ulcers based on the level of tissue injury using a staging system with uniform terminology for consistency in reporting. NPUAP defines a stage I injury as nonblanchable erythema of intact skin; stage II is partial-thickness skin loss with exposed dermis; stage III is full-thickness skin loss; stage IV is full-thickness skin and tissue loss; and a deep tissue injury is persistent nonblanchable deep red, maroon, or purple discoloration. NPUAP defines an unstageable as obscured full-thickness skin and tissue loss. [3]

Risk Factors:

- Shannon McCord conducted a case control study to identify risk factors that are associated with the development of pressure ulcers in children admitted to the pediatric intensive care unit (PICU). The results showed risk factors for pressure ulcers occurrence in children admitted to PICU were edema, prolonged length of stay, ventilated patients with high positiveend expiratory pressure (PEEP), inadequate positioning of patients and weight loss [4]

- Martha $\mathbf{C}$ conducted a study to assess the incidence, location, and factors associated with the development of pressure ulcers in patients admitted in pediatric intensive care unit (PICU). The results showed that major risk factors were patients who were on mechanical ventilator, those who had hypotension and low Braden Q scores. [5]

- Minjuan He conducted a study to determine whether skin barrier factors were associated with pressure ulcers (PrUs) intensive care unit patients. The result showed that the incidence rate of PrUs was 31.4\%. It also concluded that lower sacrum and hip skin barriers were most common risk factors for PrUs, whereas scapular and heel skin barrier factors were not. [6]

- Mary-Jeanne Manning conducted a study to identify factors associated with development of occipital pressure ulcers in acutely ill infants and children. The results showed that children at risk for occipital ulcers were patients less than 1 year old, critically ill, requiring high-risk therapies, low Braden Q score and had multiple medical devices in place. Patients with the ulcers were commonly treated with mechanical ventilation (83\%) and sedation (74\%) and were described as agitated (42\%). Many of these patients were receiving vasoactive medications (50\%) and had vascular access devices in the neck that restricted head movement (45\%). [7]

- Vocci MC conducted a retrospective study to characterize the profile of patients who developed pressure injuries. The results showed that major risk factors were male gender, the higher frequency of respiratory diseases requiring mechanical ventilation, the use of vasoactive, vasopressor and sedative drugs, and the tube as a route of dietary administration [8]

- Martha A Curley conducted a study to assess both immobility-related and medical device-related pressure injury risk in pediatric patients using Braden QD scale. The result showed that out of $8 \%$ pediatric patient who developed hospital-acquired pressure injures, $2 \%$ had immobility-related pressure injuries while 7\% had medical device-related pressure injuries. [9]

- Ivy Razmus conducted a study to assess the risk factors associated with pressure injuries in pediatric patients. Their study concluded that hospital-acquired pressure injury was more likely to occur on pediatric critical care units and rehabilitation units [10] 
- Sophia F Tam conducted a study to assess risk factors associated with pressure ulcer formation in pediatric patients on extracorporeal membrane oxygenation (ECMO). The study reported that age, weight, duration of ECMO, and femoral cannulation were the common cause that led to pressure ulcers in children who require ECMO support. [11]

- Anna-Barbara Schlüer conducted a study to assess the factors associated with pressure ulcers in pediatric patients. The results showed that the most severe PrUs occurred in patients older than 8 years. Age of the patient and department were the only characteristics that significantly influenced the occurrence of PrU categories 2 to 4. [12]

\section{Prevention of Pressure Ulcers:}

Clinical practice guidelines have served as the foundation for pressure ulcer prevention practice and treatment for more than 20 years; however, their application to pediatric patients is unknown because there are limited studies to support them.[13] The various strategies can be:

$>$ Risk Assessment: The first step in pressure ulcer prevention is to identify persons at risk. The most commonly used scales are Braden Q Scale and Neonatal Skin Risk Assessment Scale (NSRAS).

$>$ Use of pressure redistribution mattresses for critically ill children.

$>$ Repositioning patient every 2 hours, although this frequency rate may be increased or decreased based on patient risk or use of support surfaces.

$>$ Prompt cleansing of the skin using nonalkaline agents followed by application of a barrier cream

$>$ Adequate nutritional support

$>$ Skin and tissue assessment: Evaluation of patient's entire skin (from head to toe) with emphasis on bony prominences and other areas at risk for pressure ulcer development for signs or symptoms of tissue injury. Frequent assessment under and around blood pressure cuffs, transcutaneous oxygen probes, continuous positive airway devices, tracheostomies, traction, or tubes is important in the prevention of pressure ulcers from medical devices in children [14]

\section{Preventive Strategies and its relations with Pressure Ulcers}

- Janet M conducted a quasi-experimental study to o reduce the incidence of PUs > stage II in the cardiothoracic intensive care unit. The result showed that use of PU Bundle, multidisciplinary weekly skin rounds, and huddles for PUs > stage II reduced PUs related to immobility, allowed for earlier identification of stage II PUs and reduced stage III PUs. [15]

- MartaBargos-Munárriz conducted a study to evaluate effectiveness of prevention strategy for reduction in incidence and severity of positioning related pressure injuries among pediatric patients in a critical care unit. The result showed that use of prevention strategy for reduction in incidence and degree of pressure injuries was found to be effective, thereby reducing the total cumulative risk from $16 \%$ to $13.3 \%$; while in pediatric patients with longer hospital stay ( $\geq 28$ days), the incidence was reduced from $55.55 \%$ to $20 \%$. In the treatment group, grade III and IV pressure ulcers were completely reduced. Also the total number of pressure injuries was reduced to $21.43 \%$. [16]

- Chelsea P. Kriesberg conducted an interventional study to develop an evidence-based protocol designed for pressure injury prevention for neonates and children in a pediatric cardiac care unit. The study reported that in their 6 month post intervention, zero Hospital Acquired Pressure Ulcers greater than stage 2 was reported. [17]

- Xiao Chun conducted a study to evaluate the efficacy of the Braden Q Scale for the assessment of pressure ulcer risk in the pediatric intensive care unit (PICU). The study showed that Braden Q scale was effective in prevention of pressure ulcers with moderate accuracy. [18]

\section{CONCLUSION}

Patients at greatest risk are those requiring mechanical ventilation or inotropic support; those who suffer a cardiac arrest following cardiac surgery; neonates requiring extracorporeal membrane oxygenation; those with nutritional deficits, weight loss, or anasarca; and patients with longer hospital lengths of stay. Medical device-associated pressure ulcers are frequent among pediatric patients.

Declared none.

\section{ACKNOWLEDGMENT}

\section{CONFLICT OF INTEREST}

None

\section{FUNDING SOURCES}

None

\section{REFERENCES}

[1] Rowde AD, McCarty K, Huett A. Implementation of a nurse driven pathway to reduce incidence of hospital acquired pressure injuries in the pediatric intensive care setting. J Pediatr Nurs 2018;41:104-9.

[2] Schindler CA et al. Protecting fragile skin: Nursing interventions to decrease development of pressure ulcers in pediatric intensive care. Am J Crit Care 2011; 20:26-34.

[3] National Pressure Ulcer Advisory Panel. NPUAP Pressure Injury Stages. Available at:

http://www.npuap.org/resources/educational-and-clinical-resources/npuap-pressure-injury-stages/. Accessed July 13, 2021 
[4] McCord S, McElvain V, Sachdeva R, Schwartz Pand Jefferson LS. Risk factors associated with pressure ulcers in the pediatric intensive care unit. J Wound Ostomy Continence Nurs. Jul-Aug 2004;31(4):179-83.

[5] Curley MA, Quigley SM, Lin M. Pressure ulcers in pediatric intensive care: incidence and associated factors. Pediatr Crit Care Med. 2003 Jul;4(3):284-90.

[6] Minjuan He, BS; Amao Tang, MS; Xuedi Ge, BS; and Jie Zheng. Pressure Ulcers in the Intensive Care Unit: An Analysis of Skin Barrier Risk Factors. Advances in Skin \& Wound Care: November 2016; 29(11): 493-498.

[7] Manning MJ, Gauvreau K, Curley M. Factors Associated With Occipital Pressure Ulcers in Hospitalized Infants and Children. Am J Crit Care (2015) 24 (4): 342-348.

[8] Vocci MC; Onary ASS; Castro MCN; Spadotto AFO; Fontes CMB. Retrospective analysis of the application of the Braden Q scale in pediatric intensive care. ESTIMA, Braz. J. Enterostomal Ther., 2020; 18: e2820.

[9] Curley MA, et al. Predicting Pressure Injury Risk in Pediatric Patients: The Braden QD Scale. J Pediatr. Jan 2018;192:189-195.

[10] Razmus I. Factors Associated With Pediatric Hospital-Acquired Pressure Injuries. J Wound Ostomy Continence Nurs. Mar/Apr 2018;45(2):107-116.

[11] Tam SF, Mobargha A, Tobias J, Schad CA, Okochi S, Middlesworth W, Duron V. Pressure ulcers in paediatric patients on extracorporeal membrane oxygenation. Int Wound J. 2019 Apr;16(2):420-423.

[12] Schlüer AB, Schols JM, Halfens RJ. Pressure ulcer treatment in pediatric patients. Adv Skin Wound Care. Nov 2013;26(11):50410.

[13] Agency for Healthcare Research and Quality (AHRQ). Pressure Ulcer Guidelines. 1992. Available at: www.ahrq.gov. Accessed July 20, 2021.

[14] Razmus I. Pressure Ulcer Risk and Prevention Practices in Pediatric Patients: A Secondary Analysis of Data from the National Database of Nursing Quality Indicators. Wound Manangemnt and Prevention. Feb 2017; 63(2).

[15] Simsic JM, Dolan K, Howitz S, Peters S, Gajarski R. Prevention of Pressure Ulcers in a Pediatric Cardiac Intensive Care Unit. Pediatr Qual Saf. April 2019;4(3):e162.

[16] Munárriz MB, Perez MB, Martinez- Alonso AM, Molina PG, Cortes MI. Prevention of pressure injuries in critically ill children: A preliminary evaluation. Journal of Tissue Viability. November 2020; 29(4): 310-318.

[17] Kriesberg CP, Little JM, Mohr L, Kato K. Reducing Pressure Injuries in a Pediatric Cardiac Care Unit. J Wound Ostomy Continence Nurs. 2018;45(6):497-502

[18] Chun X, Lin Y, Ma J, He J, Ye L, Yang H. Predictive efficacy of the Braden Q Scale for pediatric pressure ulcer risk assessment in the PICU: a meta-analysis. Pediatr Res. 2019 Oct;86(4):436-443.

\section{AUTHORS}

First Author - Ms. Sanju Pukhraj Khawa, Nursing Officer, Department of Nursing, All India Institute of Medical Sciences, Jodhpur, Rajasthan, India. Email ID: khawasanju803@gmail.com

Correspondence Author - Ms. Sanju Pukhraj Khawa, Nursing Officer, Department of Nursing, All India Institute of Medical Sciences, Jodhpur, Rajasthan, India. Email ID: khawasanju803@gmail.com 